alluvium near Oxford, and from Germany. 3. Skull of Sz's andamanensis, forwarded him by $\mathrm{J}$. Wood Mason. 4. Skull of Sizs cristatus, lent by Sir Walter Elliott, K.C.S.T. 5. Skull of Sus barbatus wrongly named $S$. verrucosus, and needlessly Euthys barbatus in some mammalogical catalogues.

From these and other data the author bases the subjoined conclusions :-

I. The domesticated pig of Pre-Roman times, as exemplified at least by the specimens from the interment referred to, appear to resemble Sus scrofa, var. ferus, rather than S. cristatus, or the domestic variety, S. indicus.

2. On the other hand, $S$. cristatus, the Indian wild hog, appears to him, whilst being readily and always distinguishable from S. scrota, var. ferus, to differ from it, mainly by the retention permanently of certain structural conformations which were only temporarily represented in the European wild species. The third molars of the male, S. cristatzis, varied, however, concomitantly with its canines, and showed a much larger development of their posterior lobe, than either S. scrofa, var. ferus, or the females of their own species. The rearmost lobe, however, of the posterior molar, varies a good deal in $S_{1}$ scrofa, var. ftrzts, irrespective of sex.

3. Bearing in mind the elasticity of the swine type and the power for changing which their domestication has shown to possess, Dr. Rolleston has less difficulty in conceiving that the so-calied $S$. indicus was really a modified $S$. cristatus, than that it had been evolved from any Suts, such as S. iezicomystax, from countilies farther away from Europe than India. S. cristatus had the malar border of the lachrymal always marked by the relative sherrness insisted on by Nathusius. It had not the relatively wider palate; but upon this point too much weight had been laid.

4. A skull of a vild sow, from the alluvium, later in date than the "river gravels," near Oxford, combined the short lacirymal characteristic of young pigs and of $S$. cristaitus, with the worn down teeth, elongared iacial skeleton, and dis. proportionally small size of an old wild sow, S. scrofa, var. ferus. Such a combination of characteristics tended to suggest careiulness as to accepting the Torf-Schwein $S$. scrofa, var. palustris, of Ruitimeyer, as a distinct species, or taking even such a point as the shortness of the lachrymal as constituting a specific differcrice.

5. The simplicity of the third molars in the very large skull of $S$. barbatzes appear to be of greater value, as the rugose condition might have been expected to be forthcoming in so large, so well armed, and so well fed a Sus as this from Borneo.

6 . The true $S$. verrucosus differs from S. barbatus in having the lachrymal's malar edges long, relatively to its orbital, as well as in the peculiarities which its specific name implies. These peculiarities were reproduced in the old Irish "Greyhound Pig" figured by Richardson "Domestic Pigs," p. 49, Ed. Wurne.

7. The often-quoted paper by Dr. Gordon, Medical Times and Gazette, May 2, 1857, p. 429, led us to suppose that Taenia solizm of man, infested the domestic pig of India, as it does those of other parts of the world. The facility with which the pig lends itself to domestication enables us to understand how the many-sided commensalism which now exists between man and that animal may have set up in very early times. Indeed the particular results of their commensalism wtich their solidarity, as regards the alterations of the generations of Taenia solium represents, suggests that their co-existence in time must have been more extensive than even the co-existerice in space ascribed to them, not quite correctly, by Gibbon ("Decline and Fall," chap. ix. note 9, p. 392, Smith's edition).

\section{PHOTOGRAPHIC PROCESSES ${ }^{1}$}

\section{II}

WE next pass on to other applications of the dichromates for the production of prints, and the first I shall demonstrate is that known as carbon printing, but which is perhaps more correctly termed the autotype process. It is dependent on the oxidation of gelatine, one of the substances which you may have already cuessed would be capable of being acted upon by the dichromates. il, then, we have a film of this gelatine impregnated with potassium dichromate, and alter drying it be exposed to light, it will be found that all the portions acted upon will become insoluble

I Lecture by Capt. Abney, R.E., F.R.S., at the Loan Coilection, South Kensington. Continued from $\mathrm{g}, 24 \mathrm{I}$. in hot water ; that is, supposing the duration of the exposure be of sufficient duration, and if the light be sufficientiy intense. Inagine now that beneath a negative of delicate gradations of light and shade we place a film of sensitive gelatine, supported for convenience' sake on paper, and allow surilight to act upon it. After a time, in what condition will the gelatine be? It will be partially insoluble, more particularly on the surface next the negative, and the lights and shades will be represented by different depths of insolubie matter, according to the intensity of light penetrating through the various parts of the negative. I must here pause, and try and explain why this is. At first sight it might seem that the rohole of the thichness of the film ought to possess different ratios of solubility. This us not true, however; the solubility is affected to different depths. That coloured component of white light which is principally effective in producing the chemical change is blue, and which consequently finds a difficulty in piercing through the orangecoloured dichromate. The amplitude or heigit of the blue wave is continually diminished, tiil finally it is almost extinguished. Now the intenser the white light the greater will be the original amplitude of this wave, and it is at once apparent that the limit of amplitude, which is effective to cause the chemical change, wili be reached at a greater depth by those rays of light which were originally the brightest. A little reflection, then, will show you that the soluble part of the gelatine will principally be next the paper, and on immersion in hot water the viscous unaltered gelatine wolld remain insibedded between it and the outer insoluble surface. Though several ingenious methods have been tried to render the support on which the gelatine rested sufficiently porous to allow the occluded parts to be washed away, yet, so far, no attempt has been con: pletely successful. To get over the difficulty the principle has been adopted of transferring the gelatine film to a temporary support, the outside surface being caused to achere to it. Evidently, by this means, the soluble gelatine can be washed away when the paper is peeled off, and a raised image insoluble in water would remain, which eventually may be iransferred to its final support. The temporary supports, usually employed are metal plates, glass, paper coated with in insoluble compound, \&c. A picture in gelatine alone, however, would be, comparatively speaking, of little value, as it is almost coloniless; but if pigments be mixed with it the objecion disappears. In the autotype process the gelatine is mixed with colouring matter and a coating is given to a piece of paper. When dried the gelatine can be rendered serisitive by floating its surface on a solution of potassium dichromate, and after again drying is ready for printing. Such a piece of prepared paper, or carion tissue as it is technicaliy called, we have here. 'It has already been exposed beneath a negative, but no trace of any image is apparent, as the dark colour of the pigment masks it entirely. In order to judge of the amount of light received during exposure resort then is had to what are called actinometers. The detail of the instruments I will not enter into; suffice it to say it is usual to judge the depth of printing by the colour given to silver chloride. Placing then the exposed tissue, gelatine side downwards, beneath water in which a zinc plate has already been immersed, and bringing the surfaces of the two together, they are withdrawn from the water with a film of moisture between. You will notice that I left the print in the dish but a very short time, for a reason which you will presently understand. By passing this "squeegee" (which is a bar of wood from which a thick strip of india-rubber projects) over the back of the paper I drive out all the water from between the suriaces, and you see how the gelatine film clings to the zinc. And why is this? You will find that it is not naturally adhesive, the light has changed the quality of the gelatine in this respect, then why does it hold so tight to the metal plate? Simply owing to the moisture left in the paper; the soluble gelatine soaks it up and expands It cannot well expand laterally, so it expands upwards, and a partial vacuum is created between the gelatine and the plate. Now you see why I left the print in the water such a short time. Had 1 left it in longer the total expansion would have taken place, and the necessary vacuum could not have been created when it was pressed on to the zinc plate.

Now that it is firmly held, I can place it in hot water and remove the paper. It easily peels off, and the solvent action of the fluid can have fair play. As I move it up and down in the trough, you can see the gelatine running over the surface. After a few minutes it is clean, and the development is finished. On this plate I have another print which has already undergone similar treament, but has been allowed to dry. This piece of 
transfer-paper is now heated in very hot water, and applied to the surface. It is "squeegeed" on to it, and you see it adheres, this time, however, by its "stickiness." Flere is another print in the same stage, but the adhering paper is dry. Raising one corner of it by my nail, I can grasp it in my fingers, and the finished print strips off the plate held in position by the paper.

Such are the usual manipulations in autotype printing, and the pictures produced by this method should be permanent, and they must be as permanent as leather, or as the pigment which is employed to give visibility to the gelatine image. As I mentioned before, there are various modifications of the process; for instance, one is to develop the picture on the permanent support destined to bear it, using this instead of the zinc plate, A little consideration will show you that in this case the negative employed must be reversed.

We now come to a large class of printing processes known as photo-mechanical. And here I should state that the term photo-mechanical is applied to such processes as are independent of light for production of prints, after that agency has once furnished a plate or means of producing a plate. The first of these that I shall attempt to describe is that known as the Woodbury type, after the inventor, Mr. Walter Woodbury. The following outline will give some idea of the methods resorted to :-

$A$ skin of gelatine is prepared somewhat in a similar manner to that which I shall describe in the heliotype process, only for this it receives a tough film of collodion on one surface. This surface is placed next a negative on glass, and the light from an unclouded sun or from a luminous point (such as the electric light) is allowed to fall on it. Owing to the thickness of the gelatine employed, this method of exposure is necessary in order to secure sharpness. The print is developed as in the autotype process, and we get an image in great relief, formed by the insoluble gelatine, resting on the tough collodion film. When dried, this relief picture is placed on the surface of a flat, soft metal plate, and, by hydraulic pressure, is forced into it, furnishing a mould, perfect in all its parts. The wonder is at first excited that the gelatine does not break under the enormous weight brought to bear upon it, but when it is recollected that ferns and grasses can be made to furnish similar impressions, the astonishment is diminished, in that the substance employed is now in a leathery condition.

Apparently it matters little as to which side of the relief is pressed into the plate. In one case we should have to use a reversed negative, whilst in the other any ordinary negative may be employed. This is important to the photographer, as may be surnised.

Before us we have the negative, a relief from it, and a mould taken from the relief. This mould is now placed in this press, which consists of a flat plate (which can give slightly in any direction, and is capable of being raised or lowered) and a flat hirged top, to which is affixed a perfect plane of glass. When this lid is brought down on to the mould, the lower lid gives till perfect contact is got between the two surfaces; a species of clamp enables the lid to be kept in position. You see on placing this piece of paper in the mould, the clamp closes with difficulty, but a little mechanical contrivance attached to it causes a great pressure to be brought to bear. Opening the press once more, a little warm gelatine, which has been impregnated with colour, is poured on the mould, and a piece of resinised paper placed over it ; the press is again closed. The mass of cold metal soon cools the gelatine, and on opening the lid, it is found that the excess of gelatine has been squeezed out beyond the mould, and on lifting off the paper, a picture is found adhering to it. This image is really formed in precisely the same way that a cook forms her jelly in a mould, though the colouring matter in this case is somewhat different. When dry, the picture is rendered insoluble in water by passing it through an alum bath. At first sight, this process might seem to be slow, but when it is remembered that half a dozen moulds can be made from the same relief, it requires no great exercise of the imagination to surmise that the pictures may be produced almost as rapidly as a lithograph. I referred to the relief necessary to produce the mould. From what I have described it will be seen that the dried relief must be as great as the vet print of the autotype process in order to produce the same gradations.

The last process I shall describe is known as the heliotype process, and $I$ have chosen it for demonstration as I am prac. tically acquainted with its working at Chatham, and not from any inherent superiority it may possess. It is a type of all the photo-mechanical processes, if we except Woodbury, type, and it is to such as these that we must look for our book illustrations, though I am still in hopes that we may have a really good process for surface printing from a metal block, capable of being set up with type. We have a promising ex ample of this latter process in what is known as Dallastint, the offspring of Mr. Duncan Dallas; but as it is a secret process II cannot say anything regarding its production.

In the heliotype process there are variuus operations.

To begin with, there is the preparation of the gelatine film on which the image is printed.

The manner of preparing it is as follows :-Gelatine is dissolved in water by aid of heat, and to it sadded a sensitiser which con. sists of potassium dichromate, to which a small quantity of chrome alum is added. Now here I must remark that this chrome alum forms an important part of the process. Gelatine we know ordinarily dissolves in hot water, but if it be impregnated with chrome alum, not only $\mathrm{d}$.es it render the gelatine insoluble, but it also touyhens it in a marked manner when it is wetted. When the subsequent operations are explained, the importance of this property bestowed on the gelatine will be manifest. The solution of gelatine (with this sensitiser mixed in it) is flowed over a carefully levelled glass plate to such a depth that in drying it has the thickness of a piece of Bristol board. The glass plate may be ground and very slightly waxed; or it may be coated with a dilute solution of india-rubber to facilitate the gelatine leaving it, when it is required to be employed for printing purposes. A negative (which must be what is known as a reversed negative) is placed in a pressure frame, the gelatine is stripped off the plate, and the surface, which was next the glass, is in contact with the taken image. The necessary exposure may be estimated by an actinometer or by examining the image in the printing frame. When judged to be sufficiently printed, the back of the print is hardened by exposure to light. This operation gives toughness to the gelatine and renders it capable of resisting the treatment it has subsequently to undergo.

The skin of gelatine is next taken, and immersed for a few seconds in cool water (in practice a temperature of over $60^{\circ} \mathrm{F}$ is found to be the best). A pewter or other metal plate, coated with india-rul)ber, is now placed underneath it, and the film caused to adhere to it by the use of the squeegee. The pressure of the atmosphere causes the adhesion as it does in the autotype process. For convenience' sake the edges are now run round with a solution of india-rubber in benzole and paper pasted round them, to prevent the water getting beneath the skin. The plate is then immersed in cold water for about half. an-hour, to soak out the unaltered dichromate, and it is ready for use as a printing surface after the superfluous water is blotted off.

The gelatine skin is all in an insoluble state owing to the presence of the chrome alum ; but further, the part where the light has acted fully will not absorb water, whilst that which only partially absorbs water has only been partially acted on by light, and the part wholly unacted upon absorbs it greedily. When a roller con. taining greasy ink is passed over it, those parts which contain a great deal of water take no ink, particularly if it be stiff ink. The parts containing a little water take the ink lightly, whilst those parts which bave refused to imbibe any moisture take it greedily. Evidently here we have a means of obtaining a picture of half-tone subjects in printers' inl. Another point is that thin ink takes better in a partially exposed portion than does a thick ink, hence to bring out the half tone it is customary to use two or even three inks of different consistency. The printing plate is generally placed in the bed of an ordinary printing-press and rolled up with a soft roller or rollers, charged with the printing inks. The impressions are pulled off as fur litter press, though more force is necessary. In order to have clean margins a mask is cut of the proper dimensions, and lronglyt to certain register marks. The paper, usually employed for receiving the impressions, is enamelled, the enamel being formed of barium sulphate and gelatine. Any ordinary paper, however, may be used, if it have the power of taking up the ink. On the walls of the exhibition are some photographs printed on ordinary drawing paper, and they are effective in their way.

Mr. Edwards, the patentee of this process, proposed to use a series of gelatine printing surfaces from the same negative, to form a spécies of photo-chromotype, tand I have seen some specimens which are very successful. Little seems to have been done, however, in this direction at present. When drawing your attention to the manufacture of the gelatine skins there was one point to which I did not allude. You may make your skin of jelly or of blanc mange. I have found that a certain proportion of milk added to the gelatine in lieu of the water gives more delicate pictures than does gelatine 
aione. There are several kindred processes worked at present, amongst which I must notice that of the Autotype Company. In their process an exceedingly thin layer of gelatine is formed on the plate and hardened by means of gum resins. The gelatine is not removed from the plate, but it is printed from whilst still on it The film is hardened from the back. The glass plate can be inked in as described for the heliotype process, and can be puiled in a lithographic press or in an ordinary printing-press. M. Thiel, of whose process we have beautiful examples on the walls of this room, uses an ordinary lithographic printing-press.

I have only been enabled to give you a brief outline of these few processes, specimens of all of which are to be found in this exhibition. Short as have been the descriptions, I hope, however, that they have been sufficient to enable you to see the immense strides in the methods of producing prints that have been made in the last dozen years. When we consider that the autotype, the Woodbury type, and all the other mechanical printing processes have been worked out in that time, you will see that the inventive faculties of those who labour in the artscience have not been allowed to lie dormant. Perhaps in no other occupation is there such a field for discovery and improvement as in photography: and considering the many workers in it, and the large industry it represents, we may surely hope that in I886 we may again be able to record a still further advance; it may be, perhaps, in the line $I$ have already indicated, and in colour pictures.

\section{OUR ASTRONOMICAL COLUMN}

THE COMET of I686.- This comet, so far as the European observations are concerned, offers a very similar case to that of the comet of 5533 , for which two totally different orbits have long appeared in our catalogues. As regards the latter, it was shown by Olbers that the observations of Apian between July 18 and 25 were insufficient to decide whether the true direction of motion was in the order of signs or the opposite, the node at the commencement of Leo or the end of Capricornus, or the perihelion in Cancer or in Scorpio; but the publication of the Chinese observations since Olbers wrote, nas afforded evidence which tends to give the preference to his direct orbit, as already intimated in this column. The best observations of the comet of I686, are those of Père Richaud at Pau, on four mornings between September 7 and 15 ; from his positions for the 7 th, loth, and I 5 th, the following orbit was obtained, and for the sake of comparison Halley's orbit, the only one previously computed, is copied.

Ferihelion Passage, G. M.T. ... Sept. I9.2046 ... Sept. I6 6063

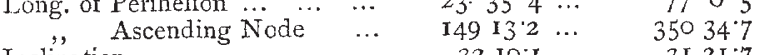

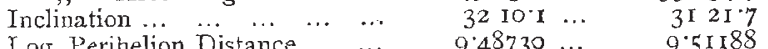

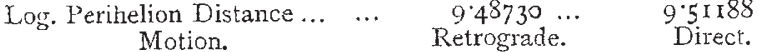

If we compare these two sets of elements with Richaud's piaces, we find the differences between calculation and observation to be, for I6h. Paris M.T., as assumed time--

$$
\begin{aligned}
& \begin{array}{r|r|}
\text { Long. New Orbit. Halley's Orbit. } & \text { Lat. } \\
\text { Long. }
\end{array}
\end{aligned}
$$

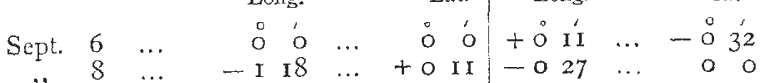

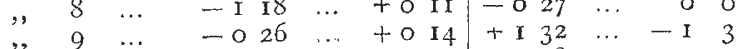

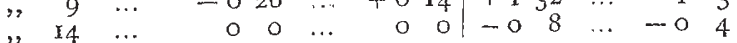

So that from these eight days' observations only it would be difficult to give a decided preference to either orbit. But it fortunately happened that before the comet was seen in Europe, it had been a very conspicuous object in more southern latitudes; at Para, in Brazil, it had been observed during the whole month of August, the nucleus as bright as stars of the first magnitude, with a tail $18^{\circ}$ in length; in Siam by the French Jesuit missionaries, who fixed its position approximately between August 17 and 23, and at Amboyna on August I5, a little south of the belt of Orion.

On comparing the two orbits with the Siam observations, it is at once evident that they decide in favour of Halley's elements, and on making a further calculation in which the August positions, which are only rough ones, are introduced, the following orbit finally results :-

Perihelion Passage, 1686, September 15.8249 G.M.T.

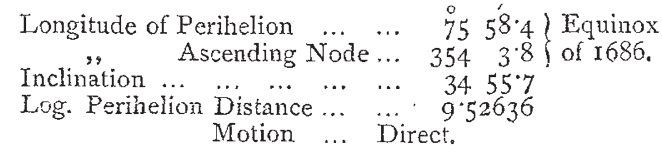

On the morning of August I7 the comet was distant from the earth $0^{\prime} 316$, and at the time of Richaud's last observation, $0^{\prime} 973$.

While writing on a cometary subject, we are reminded of what appears to be an unusual dearth of comets not of known period, in these parts of the system since the last one was detected by $M$. Borrelly on December 6,1874 , or more than eighteen months ago. It is true that generally the weather during this interval has been abnormally bad for such work as comet-hunting; still considering that several of the observers who of late years have given most attention to the search for these bodies, are located in very favoured climates, this appears hardly to explain the absence of any discovery. It may be anticipated that a systematic search for comets in the southern heavens will soon be organised by some zealous amateur in the other hemisphere; it is certain that he would in this way be likely to render material assistance in the advancement of cometary astronomy, and as we have before urged, he might succeed in bringing to light again one or two comets which were assuredly moving in elliptical orbits of short periods when last observed, but from one cause or another have since got adrift, and are not so likely to be recovered in the northern as in the southern hernisphere.

NEW MINOR PLANET.-M. Leverrier's Bulletin International of July I 3 notifies the aiscovery by $M$. Paul Henry, at the Observatory of Paris, on the previous evening, of another small planet in R.A. I 5 h. $56 \mathrm{~m}$., N.P.D. I $\mathrm{Ir}^{\circ} 59^{\prime}$. This planet, which is estimated $12.5 \mathrm{~m}$, is called No. 164, but it is to be remembered that we do not know the actual positions of so many as I 64 of these bodies, and until the elements of any newly-detected one are well determined, there is the chance of identity with one or other of several which have been previously observed and even calculated, but for want of continuous observation are now lost.

\section{A PHYSICAL SCIENCE MUSEUM}

THE President of the Royal Society, Dr. Hooker; Mr. Spottiswoode; Dr. Burdon Sanderson ; and Dr. Siemens, had an interview on the I7th inst. with the Lord President of the Council, the Duke of Richmond and Gordon, and presented the subjoined memorial from gentlemen who have been connected with the Loan Col lection of Scientific Apparatus at South Kensington. $\mathrm{H}$ is Grace discussed the subject of the proposed permanent Science Museum with the deputation, and stated that he would consult his colleagues.

\section{MY LORD DUKE,}

We, the undersigned, beg to submit for your Grace's consideration the importance of establishing a Museum of Pure and Applied Science; that is to say, a Museum. to contain Scientific Apparatus, Appliances, and Chemical Products, illustrating both the history and the latest developments of Science; where the methods and results of investigations which have marked important stages in the advancement of Science may be studied, and where also the most highly perfected instruments of the day may be found.

Among the various advantages which in our opinion would accrue from the establishment of such an Institution, 